\title{
Serum Levels of Interleukin-22 and Hepatitis B Core-related Antigen Are Associated with Treatment Response to Entecavir Therapy in Chronic Hepatitis B
}

\author{
Short running title: IL-22, HBcrAg, and ETV therapy in CH-B \\ Sadahisa Okuhara, ${ }^{1}$ Takeji Umemura,,${ }^{1}$ Satoru Joshita,,${ }^{1}$ Soichiro Shibata,${ }^{1}$ \\ Takefumi Kimura, ${ }^{1}$ Susumu Morita, ${ }^{1}$ Michiharu Komatsu, ${ }^{1}$ Akihiro Matsumoto, ${ }^{1}$ \\ Kaname Yoshizawa, ${ }^{1}$ Yoshihiko Katsuyama, ${ }^{2}$ Masao Ota, ${ }^{3}$ Eiji Tanaka ${ }^{1}$
}

1: Department of Medicine, Division of Hepatology and Gastroenterology, Shinshu University School of Medicine, Matsumoto, Japan

2: Department of Pharmacy, Shinshu University Hospital, Matsumoto, Japan

3: Department of Legal Medicine, Shinshu University School of Medicine, Matsumoto, Japan

Corresponding author: Takeji Umemura, MD, PhD

Department of Medicine, Shinshu University School of Medicine, 3-1-1 Asahi, Matsumoto 390-8621, Japan

E-mail: tumemura@shinshu-u.ac.jp; Tel.: +81-263-37-2634; Fax: +81-263-32-9412

\section{Conflict of interest:}

All authors declare no conflicts of interest. 


\section{ABSTRACT}

Aim. We sought to clarify the associations between serum cytokines and chemokines, hepatitis B surface antigen ( $\mathrm{HBsAg})$, HB core-related antigen ( $\mathrm{HBcrAg})$, and hepatitis B virus (HBV) DNA and response to entecavir therapy in chronic hepatitis $B$.

Methods. We analyzed 6 cytokines (IL-2, IL-6, IL-10, IL-12p70, IL-21, and IL-22) and 5 chemokines (CCL2, CCL3, CXCL9, CXCL10, and CXCL11) before and at 6, 12, and 24 months during entecavir therapy in 48 chronic hepatitis B patients. Quantitative measurement of $\mathrm{HBsAg}, \mathrm{HBcrAg}$, and HBV DNA was performed. A virological response (VR) was defined as serum HBV DNA $<2.1$ log copies $/ \mathrm{mL}$ by treatment month 24 .

Results. Thirty-nine patients (81\%) achieved a VR. Serum IL-6 ( $P=0.031)$, CXCL-9 $(P=$ 0.002), and CXCL-10 $(P=0.001)$ were high in chronic HBV and correlated positively with transaminases and bilirubin. Before treatment, elevated IL-22 $(P=0.031)$ and lower HBsAg $(P=0.001)$ and HBcrAg $(P<0.001)$, but not HBV DNA, were associated with a favorable treatment outcome. In multivariate analysis, high IL-22 (hazard ratio $=13.67, P$ $=0.046$ ) and low HBcrAg (hazard ratio $=10.88, P=0.048$ ) were independently associated with a VR. The levels of IL-22 $(P<0.001), \mathrm{HBsAg}(P<0.001)$, and HBcrAg $(P<0.001)$ all decreased from baseline to 24 months of treatment in virological responders. 
Conclusions. Serum IL-22 and HBcrAg are predictive markers of a VR to entecavir therapy in patients with chronic hepatitis B.

Keywords: HBV, HB core-related antigen, IL-22, HBsAg, entecavir 


\section{Introduction}

Hepatitis B virus (HBV) infection is the primary cause of cirrhosis and hepatocellular carcinoma ( $\mathrm{HCC})$ and is one of the major causes of death globally ${ }^{1,2}$. Since high plasma HBV DNA concentrations and quantitative hepatitis B surface antigen (HBsAg) levels are associated with progression to cirrhosis and development of $\mathrm{HCC}^{3,4}$, viral suppression by means of nucleos(t)ide analogue therapy has shown clinical benefits via a reduction in hepatic decompensation and lower HCC rates ${ }^{5-7}$.

Cytokines and chemokines are involved in cell-mediated and humoral immune responses as well as in antiviral activity, viral clearance, apoptosis, and fibrogenesis. As the control of cytokine production is highly complex and their effects widespread throughout multiple regulatory networks, it would seem that screening for multiple biomarkers may best clarify the immunopathogenesis of this disease and predict responses to antiviral therapy. Our previous studies have shown that several cytokines and chemokines are associated with treatment outcome in patients with chronic hepatitis C using bead-based multiplex immunoassays ${ }^{8-10}$. Although other reports have demonstrated an association between individual cytokines and clinical outcome in subjects with $\mathrm{HBV},{ }^{11-18}$ the relationship between multiple cytokines and chemokines and response to nucleos(t)ide analogue therapy in chronic hepatitis $B$ patients has not yet 
been examined in the Japanese population.

The objective of this study is to determine which cytokines and chemokines in chronic hepatitis B are related to the clinical and virologic characteristics of hepatitis and how they affect the HBV response to entecavir (ETV) treatment.

\section{Methods}

\section{Subjects.}

We enrolled 48 consecutive patients with chronic hepatitis B in this study. All patients were treatment naïve at the time of commencing ETV at a daily dose of $0.5 \mathrm{mg}$ for a duration of at least 24 months. Clinical and laboratory data of the patients were analyzed at baseline and at months 6,12 , and 24 of therapy. Chronic hepatitis B was based on HBsAg positivity for at least 6 months. No patients had a history of organ transplantation, decompensated cirrhosis, HCC, or the concurrent use of immunomodulatory drugs or corticosteroids. Patients who were coinfected with the hepatitis C virus or who exhibited evidence of other liver diseases, such as primary biliary cirrhosis, autoimmune hepatitis, alcoholic liver disease, and non-alcoholic liver disease, were excluded from this study. A group of 10 healthy individuals with hepatitis B- and C-negative serology and normal transaminase levels was used as the control. All 
patients and subjects were negative for antibodies to the human immunodeficiency virus type 1 . The protocol of this study was approved by the ethics committee of Shinshu University School of Medicine. All patients provided written informed consent.

\section{Laboratory Testing.}

HBsAg, hepatitis B e antigen (HBeAg), anti-HBe, anti-HCV, and anti-HIV-1 were determined using commercially available enzyme immunoassay kits (Abbott Japan, Tokyo, Japan) ${ }^{19}$. Serum levels of HBV DNA were quantified using the COBAS TaqMan HBV Test v2.0 (Roche Diagnostics, Tokyo, Japan) that had a dynamic range of 2.1 to 9.0 $\log$ copies $/ \mathrm{mL}$. Quantitative measurement of HBsAg was performed using an HISCL ${ }$ HBsAg assay based on the chemiluminescence enzyme immunoassay (CLEIA) (Sysmex Co. Ltd., Kobe, Japan) which had a quantitative range of -1.5 to $3.3 \log \mathrm{IU} / \mathrm{mL}$. End titer was determined by diluting samples with normal human serum when initial results exceeded the upper limit of the assay range. Serum HB core-related antigen (HBcrAg) levels were measured using a CLEIA-based HBcrAg assay kit with a fully automated Lumipulse System analyzer (Fujirebio Inc., Tokyo, Japan). We expressed HBcrAg level in terms of $\log \mathrm{U} / \mathrm{mL}$ with a quantitative range set at 3.0 to $6.8 \log \mathrm{U} / \mathrm{mL}$. HBV genotypes were determined using commercially available ELISA kits (HBV 
GENOTYPE EIA; Institute of Immunology). Serum alanine aminotransferase (ALT), aspartate aminotransferase (AST), and other relevant biochemical tests were performed using standard methods ${ }^{20}$.

\section{Definitions.}

A virological response (VR) was defined as an HBV DNA level that was undetectable by real-time PCR $(<2.1$ copies $/ \mathrm{mL})$ at 24 months. A virological breakthrough was defined as an increase in HBV DNA level by $\geq 1 \log$ copies $/ \mathrm{mL}$ above nadir while on treatment following an initial decline to $\geq 2$ log copies $/ \mathrm{mL}$.

\section{Detection of Cytokines and Chemokines.}

Six cytokines (IL-2, IL-6, IL-10, IL-12p70, IL-21, and IL-22) and 5 chemokines (CCL2/MCP-1, CCL3/MIP-1a, CXCL9/MIG, CXCL10/IP-10, and CXCL11/I-TAC) were quantified using Luminex® Multiplex Cytokine Kits (Procarta Cytokine assay kit) for serum samples obtained before the start of treatment and at weeks 24,48 , and 96 as reported previously 8,9 . These markers had been implicated in HBV pathogenesis in earlier reports ${ }^{11-16,18}$. All collected samples were immediately stored at $-70^{\circ} \mathrm{C}$ and remained in storage until testing. 


\section{Statistical Analysis.}

The Mann-Whitney $U$ test and Kruskal-Wallis test were used to analyze continuous variables where appropriate. The Friedman test was employed to evaluate changes in serum cytokine levels over time. Spearman's rank order correlations were adopted to evaluate the relationship between pairs of markers. The chi-square test with Yate's correction was used for the analysis of categorical data. In cases where the number of subjects was less than 5, we employed Fisher's exact test. A $P$ value of $<0.05$ was considered statistically significant. To predict treatment outcome, cutoff points for continuous variables were decided by receiver-operating characteristic (ROC) curve analysis with Youden's index. Factors attaining a $P$ value of $<0.1$ in univariate analysis were evaluated by multivariate analysis using a stepwise logistic regression model. These included age, HBe positivity, platelets, and levels of HBsAg, HBcrAg, HBV DNA, and IL-22 before treatment. Statistical analyses were carried out using SPSS software version 21.0J (IBM Japan Inc., Tokyo, Japan).

\section{Results}

\section{Baseline Clinical Characteristics of Patients.}


The clinical profile of the experimental patient cohort is shown in Table 1. Among our 48 patients with chronic hepatitis, 39 (81\%) achieved a VR at 24 months. A VR was attained in 11 of $20 \mathrm{HBeAg}$-positive patients (55\%) and in all $28 \mathrm{HBeAg}$-negative patients (100\%). One patient (5\%) demonstrated HBeAg seroclearance through to month 24 , but did not attain HBeAg seroconversion. No patient experienced a virological breakthrough.

The median age of patients achieving a VR was significantly higher than that of patients who did not (55 vs. 37 years; $P=0.031$ ) (Table 1). In contrast, viral responders had significantly lower median $\mathrm{HBsAg}(3.3 \mathrm{vs.} 3.9 \log \mathrm{IU} / \mathrm{mL} ; P=0.001)$ and $\mathrm{HBcrAg}(5.0$ vs. $6.8 \log \mathrm{U} / \mathrm{mL} ; P<0.001)$ levels than non-responders. We found no significant differences between patient groups with regard to sex, HBV genotype, or albumin, AST, ALT, bilirubin, or platelet levels. When stratified by HBeAg positivity, HBsAg level only was significantly associated with a VR (3.2 vs. $3.9 \log \mathrm{IU} / \mathrm{mL} ; P=0.003)$. When we compared HBeAg-positive and -negative patients, median HBV DNA and HBcrAg levels, but not HBsAg, were significantly higher in HBeAg-positive patients (Supplementary Table 1).

Detection and Quantification of Serum Markers in Patients with Chronic Hepatitis

\section{$B$ and Controls.}


Serum samples obtained prior to ETV therapy were examined for the presence of 6 cytokines and 5 chemokines by multiplex assays. As shown in Table 2, the median baseline serum concentrations of IL-6 (6.5 vs. $5.8 \mathrm{pg} / \mathrm{mL} ; P=0.031)$ and 3 chemokines (CCL2 [39.3 vs. $31.5 \mathrm{pg} / \mathrm{mL} ; P=0.022$ ], CXCL9 [329.2 vs. $127.8 \mathrm{pg} / \mathrm{mL} ; P=0.002$ ], and CXCL10 [217.1 vs. $58.7 \mathrm{pg} / \mathrm{mL} ; P=0.001])$ were significantly higher in patients with chronic hepatitis B than in healthy controls. When we sub-divided patients into HBeAg-positive or anti-HBe-positive groups, no significant differences in the median concentrations of any cytokine or chemokine were seen, including IL-22 (Supplementary Table 1).

\section{Effect of Entecavir Therapy on Serum Cytokine Levels.}

The median levels of serum cytokines and chemokines in our cohort are shown

in Table 3. Among our patients, the median baseline serum IL-22 concentration was significantly higher in virological responders than in non-responders (35.3 vs. 27.8 $\mathrm{pg} / \mathrm{mL} ; P=0.031$ ) (Figure 1A). No other cytokines or chemokines were associated with a VR. When stratified by HBeAg positivity, serum IL-22 and IL-6 levels in the VR group were significantly higher than those in the non-VR group (35.3 vs. $31.2 \mathrm{pg} / \mathrm{mL} ; P=0.046$ and 6.9 vs. $6.1 \mathrm{pg} / \mathrm{mL} ; P=0.031$, respectively). 
Several clinical findings (HBV DNA, HBsAg, HBcrAg, albumin, AST, ALT, bilirubin, and platelet) at baseline were examined for their correlation with serum cytokines or chemokines in patients with chronic hepatitis B. Serum IL-6, CXCL9, CXCL10, and CXCL11 were all positively correlated with values for AST, ALT, and bilirubin, but were negatively correlated with serum HBsAg (Table 4). CXCL9, CXCL10, and CXCL11 were also significantly correlated with each other (data not shown). There was a negative correlation between HBsAg and AST, ALT, and bilirubin (data not shown).

\section{Prediction of Viral Response in Patients with Chronic Hepatitis B.}

We performed ROC curve analysis to determine the optimal cutoff values for serum IL-22, HBsAg, and HBcrAg in predicting a VR for chronic HBV infection with the values obtained from the 39 patients who achieved a VR and the 9 who did not. The selection of optimal cutoff point values was based on the IL-22, HBsAg, and HBcrAg levels at which accuracy was maximal. Optimal cutoff value, sensitivity, specificity, positive predictive value, negative predictive value, and calculated area under the curve (AUC) for each parameter are listed in Table 5. The AUC values were consistently high and ranged between 0.731 (IL-22) and 0.858 (HBcrAg).

Several factors found in association with a VR to ETV therapy were evaluated for 
their independence by multivariate analysis. We determined that IL-22 $\geq 27.8 \mathrm{pg} / \mathrm{mL}$ (hazard ratio: 13.67 [95\% confidence interval $(\mathrm{Cl}) 1.05-178.11], P=0.046)$ and $\mathrm{HBcrAg} \leq$ $5.7 \log \mathrm{U} / \mathrm{mL}$ (hazard ratio: 10.88 [95\% Cl 1.02-115.44], $P=0.048$ ) were independent factors related to a VR. HBsAg did not have a significant independent association in this study $(P=0.071)$.

\section{Serum Cytokine and Chemokine Changes during Treatment.}

Longitudinal analysis of IL-22, HBsAg, and HBcrAg levels was carried out at 6, 12, and 24 months after the initiation of therapy and showed significant gradual reductions in IL-22 $(P<0.001$, Friedman test), HBsAg $(P<0.001)$, and $\mathrm{HBcrAg}(P<$ 0.001) in samples collected from patients who achieved a VR (Figure 1 A, B, and C). We noted a higher median serum IL-22 concentration at month 6 in the VR group than in the non-VR group $(P=0.012)$, and there were significant differences at each time point for HBsAg (6 months; $P=0.002,12$ months; $P=0.006$, and 24 months; $P=0.004$ ) and HBcrAg (6 months; $P<0.001,12$ months; $P<0.001$, and 24 months; $P<0.001$ ) between responders and non-responders.

\section{Discussion}


In the present study, we measured the levels of 6 cytokines and 5 chemokines in patients with chronic hepatitis B and analyzed their association with ETV therapy outcome using a bead-array multiplex immunoassay system. Four of our observations are noteworthy and require further comment. First, serum IL-6, CCL2, CXCL9, and CXCL10 concentrations were higher in patients with chronic hepatitis B than in healthy subjects. Second, serum IL-22 concentration before treatment was significantly higher in patients achieving a VR to ETV therapy. In contrast, responders had lower serum levels of HBsAg and HBcrAg at baseline. Third, IL-22, HBsAg, and HBcrAg decreased during treatment and remained low in patients with a VR. Fourth, serum IL-6, CXCL9, CXCL10, and CXCL11 were positively correlated with serum values of AST, ALT, and bilirubin, but were negatively correlated with HBsAg.

IL-6 is a well-recognized multifunctional cytokine that may reflect more active hepatic necro-inflammation and be associated with chronic HBV infection severity. As in previous studies ${ }^{18,21}$, serum IL-6 was significantly higher in the HBV-infected group than in healthy controls and was positively correlated with such clinical parameters as transaminases and bilirubin. Hence, our data support that IL-6 is strongly associated with the severity of liver diseases.

CXCL9, CXCL10, and CXCL11 appear to be particularly important in chronic 
hepatitis $C$ virus infection by promoting the development of intrahepatic inflammation that leads to fibrogenesis ${ }^{22,23}$. These chemokines are also significantly elevated in patients with necro-inflammatory activity of acute and chronic hepatitis C 24,25 . In our study, serum CXCL9 and CXCL10 were higher in patients with chronic HBV infection than in healthy individuals, which was in agreement with a previous report ${ }^{12}$. Moreover, the serum CXCR3-associated chemokines CXCL9, CXCL10, and CXCL11 were all well correlated with serum values of AST, ALT, and bilirubin. Since we observed a significant correlation between these chemokines and IL-6, our findings suggest that CXCR3-associated chemokines may too contribute to necro-inflammatory activity in chronic HBV infection. However, there were insufficient histological data in our study to assess whether IL-6 and CXCR3-associated chemokines were correlated with degree of fibrosis, in addition to a lack of biochemical evidence of inflammation. We furthermore showed a striking negative association between HBsAg concentration and levels of IL-6 and CXCR3-associated chemokines. As HBsAg was also negatively correlated with transaminases and bilirubin, this HBsAg decline might be linked to increased immunological activity.

Interestingly, this study demonstrated a beneficial role of IL-22 in achieving a VR during ETV therapy. IL-22 is an IL-10 family cytokine that is important for the modulation 
of tissue responses during inflammation and is expressed by many types of lymphocytes of both the innate and adaptive immune systems, most notably $T$ helper 17 cells, $ү \delta T$ cells, natural killer cells, and lymphoid tissue inducer-like cells. The IL-22 receptor is highly expressed on hepatocytes ${ }^{26,27}$. At present, several studies support a protective role of IL-22 in the prevention of hepatocellular damage, although there is evidence indicating dual protective and pathogenic roles for this cytokine in the liver ${ }^{17,} 28-30$. Some groups have examined the association between IL-22 and liver fibrosis in humans and mice ${ }^{31,32}$. In one report, tumor-infiltrating lymphocytes in HCC exhibited elevated IL-22 expression, and these IL-22+ lymphocytes promoted tumor growth and metastasis in mice ${ }^{33}$. Although human patients with chronic hepatitis B show increased percentages of T helper 17 cells in the peripheral blood and liver and an increased concentration of IL-22 in the serum ${ }^{14,34}$, there have been no reports on treatment outcome in patients with chronic HBV infection during ETV therapy. In our study, IL-22 levels decreased over time in both the VR and non-VR groups, but they were consistently higher in the VR group. This difference in IL-22 levels between the two groups further supports the possibility that IL-22 may be important for the activation of immune cells that contribute to viral control. When stratified by $\mathrm{HBe}$ positivity, although IL-22 was still significantly associated with a VR, the number of patients was only 20 in this study. Further research 
is needed to clarify the association between IL-22 and treatment response.

Lastly, we uncovered that lower baseline serum HBsAg and HBcrAg levels were associated with a VR. HBcrAg assays measure serum levels of HB core, e, and 22-kDa precore antigens simultaneously using monoclonal antibodies that recognize the common epitopes of these three denatured antigens ${ }^{35}$. Since this assay measures all antigens transcribed from the precore/core gene, it is regarded as core-related ${ }^{36}$. The AUC values for baseline $\mathrm{HBsAg}$ and $\mathrm{HBcrAg}$ levels were high at 0.838 and 0.858 , respectively. Several studies have shown that HBsAg is useful for the management of ETV therapy ${ }^{37,38}$, whereby an $\mathrm{HBsAg}$ decline is most profound in patients losing $\mathrm{HBeAg}$ detectability during treatment ${ }^{39}$. HBeAg positivity was also significantly associated with treatment outcome in the present study. However, since HBcrAg, but not HBsAg or $\mathrm{HBeAg}$, was an independent factor related to a VR in multivariate analysis, our results indicated that serum HBcrAg quantitation may offer clinicians a new tool in predicting treatment outcome in HBV infection. Further investigation of large cohorts must be done to validate the significance of our findings.

With a VR at 12 months established as a parameter, 38 patients $(79 \%)$ achieved this event. Serum IL-22, HBsAg, and HBcrAg levels were all still significantly associated with a VR at 12 months. AUC values were as high as between 0.737 (IL-22) 
and 0.878 (HBcrAg). Furthermore, ALT normalization was achieved in $40(83 \%)$ and 42 (88\%) patients at 12 and 24 months, respectively. Although lower median pretreatment levels of HBsAg and HBcrAg were significantly associated with ALT normalization, there was no such statistically significant relation for IL-22 (data not shown).

In summary, a cytokine (IL-6) and several chemokines (CCL2, CXCL9, and CXCL10) were seen to be elevated in patients with chronic hepatitis B. Our results indicate that serum IL-6 and CXCR3-associated chemokines are correlated with liver injury, serum IL-22 is a useful biomarker for predicting a VR to ETV therapy, and a lower level of serum HBcrAg is related to a favorable response to antiviral therapy.

Acknowledgments: This research was supported in part by a research grant from the Ministry of Health, Labor, and Welfare of Japan. The authors thank Yuki Akahane, Asami Yamazaki, and Toyo Amaki for their technical assistance, and Trevor Ralph for his English editorial assistance. 


\section{References}

$1 \quad$ Lee WM. Hepatitis B virus infection. N Engl J Med 1997;337: 1733-45.

2 Umemura T, Ichijo T, Yoshizawa K, Tanaka E, Kiyosawa K. Epidemiology of hepatocellular carcinoma in Japan. J Gastroenterol 2009;44 Suppl 19: 102-7.

3 Chen CJ, Yang HI, Su J, et al. Risk of hepatocellular carcinoma across a biological gradient of serum hepatitis B virus DNA level. Jama 2006;295: 65-73.

$4 \quad$ lloeje UH, Yang HI, Su J, Jen CL, You SL, Chen CJ. Predicting cirrhosis risk based on the level of circulating hepatitis B viral load. Gastroenterology 2006;130: 678-86.

5 Dienstag JL, Goldin RD, Heathcote EJ, et al. Histological outcome during long-term lamivudine therapy. Gastroenterology 2003;124: 105-17.

6 Liaw YF, Sung JJ, Chow WC, et al. Lamivudine for patients with chronic hepatitis B and advanced liver disease. N Engl J Med 2004;351: 1521-31.

7 Hosaka T, Suzuki F, Kobayashi M, et al. Long-term entecavir treatment reduces hepatocellular carcinoma incidence in patients with hepatitis B virus infection. Hepatology 2013;58: 98-107.

8 Yoneda S, Umemura T, Katsuyama Y, et al. Association of serum cytokine levels with treatment response to pegylated interferon and ribavirin therapy in genotype 1 chronic hepatitis $C$ patients. $J$ Infect Dis 2011;203: 1087-95.

9 Yoneda S, Umemura T, Joshita S, et al. Serum chemokine levels are associated with the outcome of pegylated interferon and ribavirin therapy in patients with chronic hepatitis C. Hepatol Res 2011;41: 587-93.

10 Umemura T, Joshita S, Yoneda S, et al. Serum interleukin (IL)-10 and IL-12 levels and IL28B gene polymorphisms: pretreatment prediction of treatment failure in chronic hepatitis C. Antivir Ther 2011;16: 1073-80.

$11 \mathrm{Wu}$ JF, Wu TC, Chen $\mathrm{CH}$, et al. Serum levels of interleukin-10 and interleukin-12 predict early, spontaneous hepatitis B virus e antigen seroconversion. Gastroenterology 2010;138: 165-72 e1-3.

12 Tan AT, Koh S, Goh W, et al. A longitudinal analysis of innate and adaptive immune profile during hepatic flares in chronic hepatitis B. J Hepatol 2010;52: 330-9.

13 Publicover J, Goodsell A, Nishimura S, et al. IL-21 is pivotal in determining age-dependent effectiveness of immune responses in a mouse model of human hepatitis B. J Clin Invest 2011;121: 1154-62.

14 Zhang $\mathrm{Y}$, Cobleigh MA, Lian JQ, et al. A proinflammatory role for interleukin-22 in the immune response to hepatitis B virus. Gastroenterology 2011;141: 1897-906.

15 Ma SW, Huang X, Li YY, et al. High serum IL-21 levels after 12 weeks of antiviral therapy predict HBeAg seroconversion in chronic hepatitis B. J Hepatol 2012;56: 775-81.

16 Tacke F, Zimmermann HW, Berres ML, Trautwein C, Wasmuth HE. Serum chemokine receptor 
CXCR3 ligands are associated with progression, organ dysfunction and complications of chronic liver diseases. Liver Int 2011;31: 840-9.

17 Feng $\mathrm{D}$, Kong $\mathrm{X}$, Weng $\mathrm{H}$, et al. Interleukin-22 promotes proliferation of liver stem/progenitor cells in mice and patients with chronic hepatitis B virus infection. Gastroenterology 2012;143: 188-98 e7.

18 Pan CJ, Wu HL, Kuo SF, et al. Serum interleukin 6 level correlates with outcomes of acute exacerbation of chronic hepatitis B. Hepatology international 2012;6: 591-7.

19 Umemura T, Tanaka E, Kiyosawa K, Kumada H. Mortality secondary to fulminant hepatic failure in patients with prior resolution of hepatitis B virus infection in Japan. Clin Infect Dis 2008;47: e52-6.

20 Umemura T, Zen Y, Hamano H, Kawa S, Nakanuma Y, Kiyosawa K. Immunoglobin G4-hepatopathy: association of immunoglobin G4-bearing plasma cells in liver with autoimmune pancreatitis. Hepatology 2007;46: 463-71.

21 Kao JT, Lai HC, Tsai SM, et al. Rather than interleukin-27, interleukin-6 expresses positive correlation with liver severity in naive hepatitis B infection patients. Liver Int 2012;32: 928-36.

22 Zeremski M, Petrovic LM, Talal AH. The role of chemokines as inflammatory mediators in chronic hepatitis C virus infection. J Viral Hepat 2007;14: 675-87.

23 Heydtmann M, Adams DH. Chemokines in the immunopathogenesis of hepatitis C infection. Hepatology 2009;49: 676-88.

24 Zeremski M, Petrovic LM, Chiriboga L, et al. Intrahepatic levels of CXCR3-associated chemokines correlate with liver inflammation and fibrosis in chronic hepatitis C. Hepatology 2008;48: 1440-50.

25 Zeremski M, Hooker G, Shu MA, et al. Induction of CXCR3- and CCR5-associated chemokines during acute hepatitis $C$ virus infection. $J$ Hepatol 2011;55: 545-53.

26 Colonna M. Interleukin-22-producing natural killer cells and lymphoid tissue inducer-like cells in mucosal immunity. Immunity 2009;31: 15-23.

27 Zenewicz LA, Flavell RA. Recent advances in IL-22 biology. Int Immunol 2011;23: 159-63.

28 Zenewicz LA, Yancopoulos GD, Valenzuela DM, Murphy AJ, Karow M, Flavell RA. Interleukin-22 but not interleukin-17 provides protection to hepatocytes during acute liver inflammation. Immunity 2007;27: 647-59.

29 Ki SH, Park O, Zheng M, et al. Interleukin-22 treatment ameliorates alcoholic liver injury in a murine model of chronic-binge ethanol feeding: role of signal transducer and activator of transcription 3. Hepatology 2010;52: 1291-300.

30 Park $\mathrm{O}$, Wang $\mathrm{H}$, Weng $\mathrm{H}$, et al. In vivo consequences of liver-specific interleukin-22 expression in mice: Implications for human liver disease progression. Hepatology 2011;54: 252-61.

31 Kong $\mathrm{X}$, Feng $\mathrm{D}$, Wang $\mathrm{H}$, et al. Interleukin-22 induces hepatic stellate cell senescence and restricts liver fibrosis in mice. Hepatology 2012;56: 1150-9.

32 Meng F, Wang K, Aoyama T, et al. Interleukin-17 signaling in inflammatory, Kupffer cells, and 
hepatic stellate cells exacerbates liver fibrosis in mice. Gastroenterology 2012;143: 765-76 e1-3.

33 Jiang R, Tan Z, Deng L, et al. Interleukin-22 promotes human hepatocellular carcinoma by activation of STAT3. Hepatology 2011;54: 900-9.

34 Zhang JY, Zhang Z, Lin F, et al. Interleukin-17-producing CD4(+) T cells increase with severity of liver damage in patients with chronic hepatitis B. Hepatology 2010;51: 81-91.

35 Kimura T, Ohno N, Terada N, et al. Hepatitis B virus DNA-negative dane particles lack core protein but contain a $22-\mathrm{kDa}$ precore protein without C-terminal arginine-rich domain. $\mathrm{J}$ Biol Chem 2005;280: 21713-9.

36 Kimura T, Rokuhara A, Sakamoto $Y$, et al. Sensitive enzyme immunoassay for hepatitis B virus core-related antigens and their correlation to virus load. J Clin Microbiol 2002;40: 439-45.

37 Lee JM, Ahn SH, Kim HS, et al. Quantitative hepatitis B surface antigen and hepatitis B e antigen titers in prediction of treatment response to entecavir. Hepatology 2011;53: 1486-93.

38 Liaw YF. Clinical utility of hepatitis B surface antigen quantitation in patients with chronic hepatitis B: a review. Hepatology 2011;54: E1-9.

39 Reijnders JG, Rijckborst V, Sonneveld MJ, et al. Kinetics of hepatitis B surface antigen differ between treatment with peginterferon and entecavir. J Hepatol 2011;54: 449-54. 
Figure Legend

Figure 1. Comparison of Serum (A) IL-22, (B) HBsAg, and (C) HBcrAg Levels during Entecavir Therapy in the VR $(n=39)$ and non-VR $(n=9)$ Groups.

Boxes represent the interquartile range of the data. The lines across the boxes indicate the median values. The harsh marks above and below the boxes indicate the $90^{\text {th }}$ and $10^{\text {th }}$ percentiles for each group, respectively.

IL, interleukin; HBsAg, hepatitis B surface antigen; HBcrAg, hepatitis core-related antigen; VR, virological response. 
Table 1. Demographic and Clinical Characteristics of 48 Patients with Chronic

\section{Hepatitis B}

\begin{tabular}{|c|c|c|c|c|}
\hline Characteristics & $\begin{array}{l}\text { Total } \\
\mathrm{n}=48\end{array}$ & $\begin{array}{l}\text { VR (+) } \\
\mathrm{n}=39\end{array}$ & $\begin{array}{l}\text { VR (-) } \\
\mathrm{n}=9\end{array}$ & $P$ \\
\hline Age, years & $55(24-81)$ & $55(24-81)$ & $37(26-67)$ & 0.031 \\
\hline Male, n (\%) & $33(69)$ & $29(74)$ & $4(44)$ & 0.18 \\
\hline HBeAg-positive, n (\%) & $20(42)$ & $11(28)$ & $9(100)$ & $<0.001$ \\
\hline HBV genotype C, n (\%) & $45(94)$ & $37(95)$ & $8(89)$ & 1.00 \\
\hline HBV DNA (log copies/mL) & $6.6(2.7->9.1)$ & $6.4(2.7->9.1)$ & $8.0(3.9->9.1)$ & 0.06 \\
\hline HBsAg (log IU/mL) & $3.4(-1.2-4.5)$ & $3.3(-1.2-4.3)$ & $3.9(3.3-4.5)$ & 0.001 \\
\hline HBcrAg (log U/mL) & $5.2(3.0-6.8)$ & $5.0(3.0-6.8)$ & $6.8(5.4-6.8)$ & $<0.001$ \\
\hline Albumin (mg/dL) & $4.2(2.3-5.3)$ & $4.2(3.1-5.3)$ & $4.2(2.3-4.5)$ & 0.80 \\
\hline AST (IU/L) & $48(15-1476)$ & $51(15-1476)$ & $36(28-358)$ & 0.82 \\
\hline ALT (IU/L) & $49(9-2021)$ & $63(9-2021)$ & $56(29-954)$ & 0.74 \\
\hline Bilirubin (mg/dL) & $0.8(0.3-3.1)$ & $0.8(0.3-3.1)$ & $0.7(0.5-1.0)$ & 0.33 \\
\hline Platelet $(/ \mu \mathrm{L})$ & $16.3(8.0-28.9)$ & $15.2(8.0-28.9)$ & $19.5(11.9-27.7)$ & 0.053 \\
\hline
\end{tabular}

Continuous variables are expressed as median values (range).

AST, aspartate aminotransferase; ALT, alanine aminotransferase; $\mathrm{HBeAg}$, hepatitis $B$ e-antigen; HBV, hepatitis B virus; HBcrAg, hepatitis B core-related antigen; HBsAg, hepatitis B surface antigen. 
Table 2. Serum Cytokines and Chemokines in Patients with Chronic Hepatitis B and Healthy Subjects

\begin{tabular}{cccc}
\hline Cytokine/Chemokine & Patients & Controls & $P$ value \\
\hline IL-2 & $2.3(0-4.9)$ & $2.1(1.9-2.4)$ & 0.42 \\
IL-6 & $6.5(2.7-19.1)$ & $5.8(5.8-6.5)$ & 0.031 \\
IL-10 & $1.1(0.0-26.8)$ & $1.4(1.3-1.6)$ & 0.49 \\
IL-12p70 & $12.9(0.1-22.0)$ & $12.9(12.8-12.9)$ & 0.50 \\
IL-22 & $12.5(5.0-1916.5)$ & $11.5(10.5-253.5)$ & 0.68 \\
CCL2 & $34.9(27.2-75.7)$ & $33.6(32.3-39.0)$ & 0.47 \\
CCL3 & $39.3(23.8-8118.8)$ & $31.5(26.7-39.3)$ & 0.022 \\
CXCL9 & $4.8(0.0-651.8)$ & $7.0(5.0-9.9)$ & 0.25 \\
CXCL10 & $217.1(18.6-3594.3)$ & $58.7(24.7-859.5)$ & 0.001 \\
CXCL11 & $40.8(0.7-553.8)$ & $25.8(12.9-90.3)$ & 0.23 \\
\hline IL, interleukin. & & & \\
\hline
\end{tabular}


Table 3. Serum Cytokines and Chemokines in Treatment Outcome to Antiviral Therapy

\begin{tabular}{cccc}
\hline Cytokine/Chemokine & VR & Non-VR & $P$ value \\
\hline IL-2 & $2.3(0.0-4.9)$ & $3.1(0.0-3.3)$ & 0.60 \\
IL-6 & $6.8(2.7-19.1)$ & $6.1(4.3-12.5)$ & 0.22 \\
IL-10 & $0.6(0.0-26.8)$ & $1.5(0.0-5.0)$ & 0.86 \\
IL-12p70 & $12.9(0.1-22.0)$ & $12.9(1.2-18.0)$ & 0.74 \\
IL-21 & $12.2(5.0-1916.5)$ & $19.9(5.9-27.8)$ & 0.70 \\
IL-22 & $35.3(27.2-75.7)$ & $27.8(27.3-46.7)$ & 0.031 \\
CCL2 & $40.8(24.4-118.8)$ & $34.8(23.8-60.3)$ & 0.13 \\
CCL3 & $4.5(0.0-651.8)$ & $6.5(2.7-22.9)$ & 0.57 \\
CXCL9 & $322.5(115.4-18758.9)$ & $353.6(89.8-1545.1)$ & 0.60 \\
CXCL10 & $206.3(29.1-3594.3)$ & $294.2(18.6-2240.7)$ & 0.94 \\
CXCL11 & $39.9(0.7-553.8)$ & $48.8(12.6-428.2)$ & 0.80 \\
\hline Continuous variables are expressed as median values (range) (pg/mL). & \\
IL, interleukin. & & & \\
\hline & & & \\
\hline
\end{tabular}


Table 4. Correlation between Cytokines, Chemokines, and Clinical Parameters

\begin{tabular}{|c|c|c|c|c|c|c|c|c|c|c|c|c|}
\hline & & IL-2 & IL-6 & IL-10 & IL-12 & IL-21 & IL-22 & CCL2 & CCL3 & CXCL9 & CXCL10 & CXCL11 \\
\hline \multirow{2}{*}{ HBV DNA } & $r$ & 0.08 & 0.01 & 0.10 & 0.06 & 0.08 & 0.17 & -0.13 & 0.01 & -0.13 & -0.10 & 0.20 \\
\hline & $P$ & 0.61 & 0.97 & 0.51 & 0.69 & 0.61 & 0.25 & 0.39 & 0.95 & 0.39 & 0.50 & 0.18 \\
\hline \multirow{2}{*}{$\mathrm{HBsAg}$} & $r$ & -0.99 & -0.35 & -0.14 & 0.22 & -0.08 & -0.05 & -2.5 & 0.02 & -0.78 & -0.61 & -0.32 \\
\hline & $P$ & 0.51 & 0.015 & 0.35 & 0.14 & 0.61 & 0.74 & 0.09 & 0.89 & $<0.001$ & $<0.001$ & 0.025 \\
\hline \multirow{2}{*}{ HBcrAg } & $r$ & 0.04 & 0.05 & -0.16 & 0.24 & 0.18 & 0.14 & -0.13 & 0.14 & -0.14 & -0.15 & 0.11 \\
\hline & $P$ & 0.79 & 0.76 & 0.29 & 0.11 & 0.21 & 0.35 & 0.40 & 0.33 & 0.36 & 0.31 & 0.45 \\
\hline \multirow{2}{*}{ Albumin } & $r$ & 0.17 & 0.02 & 0.17 & -0.02 & 0.05 & -0.02 & 0.12 & 0.08 & 0.13 & -0.09 & 0.02 \\
\hline & $P$ & 0.25 & 0.91 & 0.24 & 0.89 & 0.75 & 0.88 & 0.40 & 0.60 & 0.39 & 0.53 & 0.91 \\
\hline \multirow{2}{*}{ AST } & $r$ & 0.05 & 0.40 & 0.11 & -0.11 & -0.03 & 0.14 & 0.13 & -0.07 & 0.78 & 0.75 & 0.36 \\
\hline & $P$ & 0.72 & 0.004 & 0.45 & 0.47 & 0.83 & 0.33 & 0.39 & 0.66 & $<0.001$ & $<0.001$ & 0.013 \\
\hline \multirow{2}{*}{ ALT } & $r$ & 0.02 & 0.42 & 0.12 & -0.11 & -0.06 & 0.16 & 0.10 & -0.08 & 0.69 & 0.71 & 0.46 \\
\hline & $P$ & 0.91 & 0.003 & 0.40 & 0.44 & 0.70 & 0.28 & 0.52 & 0.57 & $<0.001$ & $<0.001$ & 0.001 \\
\hline \multirow{2}{*}{ Bilirubin } & $r$ & -0.03 & 0.36 & 0.07 & 0.08 & -0.03 & 0.13 & 0.27 & -0.12 & 0.33 & 0.65 & 0.35 \\
\hline & $P$ & 0.83 & 0.012 & 0.64 & 0.58 & 0.84 & 0.38 & 0.07 & 0.42 & 0.023 & $<0.001$ & 0.015 \\
\hline
\end{tabular}




\begin{tabular}{lllllllllllllll}
\hline \multirow{2}{*}{ Platelet } & $r$ & 0.08 & 0.12 & 0.15 & -0.09 & 0.13 & 0.25 & -0.05 & 0.19 & 0.31 & 0.04 & 0.13 \\
& $P$ & 0.57 & 0.42 & 0.33 & 0.55 & 0.38 & 0.09 & 0.74 & 0.20 & 0.033 & 0.82 & 0.39 \\
\hline
\end{tabular}

HBV, hepatitis B virus; HBcrAg, hepatitis B core-related antigen; HBsAg, hepatitis B surface antigen; AST, aspartate aminotransferase; ALT, alanine aminotransferase; IL, interleukin; r, Spearman's rank correlation. 
Table 5. Optimal Cutoff Value, Sensitivity, Specificity, AUC, and Predictive Value of Serum IL-22, HBsAg, and HBcrAg at Baseline of Treatment in 48 Patients with Chronic Hepatitis B

\begin{tabular}{|c|c|c|c|c|c|c|}
\hline & \multirow{3}{*}{ Cutoff value } & Sensitivity (\%) & Specificity (\%) & AUC & \multirow{3}{*}{ PPV (\%) } & \multirow{3}{*}{ NPV $(\%)$} \\
\hline & & & & & & \\
\hline & & $(95 \% \mathrm{Cl})$ & $(95 \% \mathrm{Cl})$ & $(95 \% \mathrm{Cl})$ & & \\
\hline IL-22 & $27.8 \mathrm{pg} / \mathrm{mL}$ & $56(21-86)$ & $90(76-97)$ & $0.731(0.533-0.929)$ & 90 & 56 \\
\hline $\mathrm{HBsAg}$ & $3.6 \log \mathrm{IU} / \mathrm{mL}$ & $78(40-97)$ & $77(61-89)$ & $0.838(0.704-0.971)$ & 44 & 94 \\
\hline $\mathrm{HBcrAg}$ & $5.7 \log U / \mathrm{mL}$ & $89(52-100)$ & $82(67-93)$ & $0.858(0.754-0.962)$ & 53 & 97 \\
\hline
\end{tabular}

AUC, area under the curve; $\mathrm{Cl}$, confidence interval; PPV, positive predictive value; NPV, negative predictive value; IL, interleukin; HBsAg, hepatitis B surface antigen; HBcrAg, hepatitis core-related antigen.

All AUC values were significantly higher than a 0.50 nonpredictive value $(P<0.01$ for all comparisons). Cutoff values were determined by constructing receiver operating characteristic curves. 